Jones, K. (2011), The value of learning geometry with ICT: lessons from innovative educational research. In Adrian Oldknow and Carol Knights (Eds), Mathematics

Education with Digital Technology. London: Continuum. (chapter 5, pp.39-45). ISBN: 9781441184726

Chapter 5

\title{
The Value of Learning Geometry with ICT: Lessons from Innovative Educational Research
}

\author{
Keith Jones \\ University of Southampton, UK
}

\begin{abstract}
Introduction
The 40th anniversary of the launch of the British Journal of Educational Technology (BJET) took place in 2009. Also in 2009, coincidentally, ATM instigated MTi (Mathematics Teaching interactive), an online web-based publication. The first issue of BJET (in 1970) was most concerned with the availability of audio-visual resources (such as $16 \mathrm{~mm}$ film projectors), whereas the first issue of MTi contained, amongst other things, an article which reports on using geometry software to discover (and in some cases prove) some of the circle theorems, and another which examines questions for which the answer is "It's a parabola" (see Figure 1 for an example from nature).
\end{abstract}

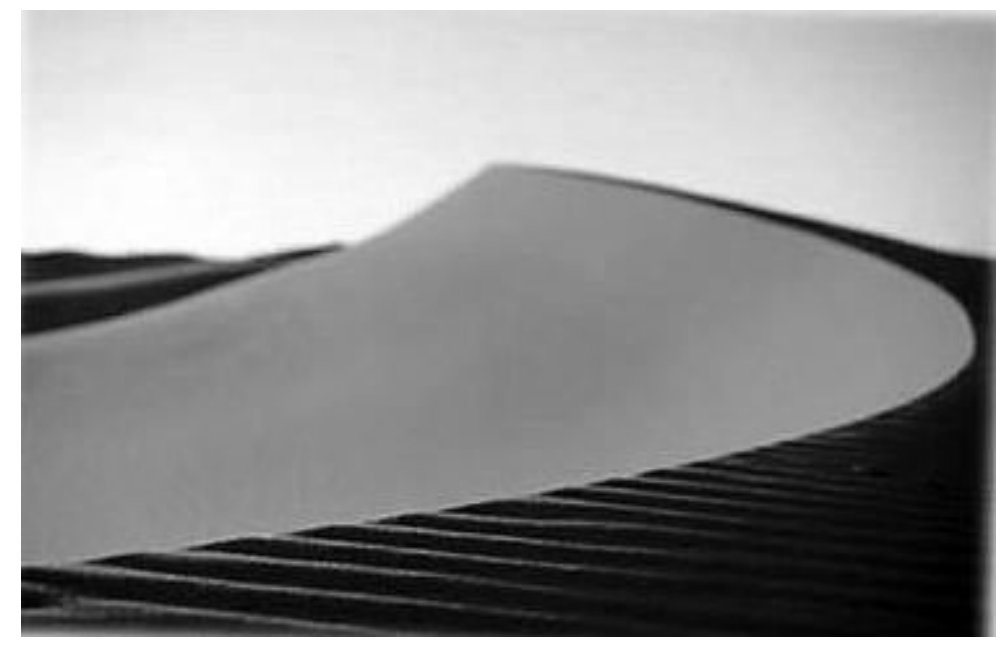

FIGURE 5.1: Sand Dune in Morocco (photo by Fabio Cologna) 
Initiatives such as MTi are symptomatic of the changes in technology that have taken place over the period since the launch of BJET - computing power has become more ubiquitous, technologies have converged, and the emphasis is increasingly on interactivity that exploits users' visual and spatial intuition. All this means that, in reviewing the value of learning school mathematics with ICT, it is instructive to focus on geometry especially as geometry is both a key component of mathematical theory, and the quintessential visual and spatial element (Jones, 2002a).

In what follows, the research selected focuses on learners' use of interactive geometry software, the design of suitable teaching and learning activities, and the nature of relevant teacher professional development. The central theme of the chapter is that while ICT has considerable potential in enlivening the teaching and learning of school mathematics (and geometry in particular), there is much to take account of in terms of enabling this potential to be fully realised.

The visual and spatial interactivity offered by ICT means that dynamic geometry software (examples include Cabri, GeoGebra, Sketchpad, etc) has become perhaps the best-researched in mathematics education (for a review, see Jones, 2002b). At first glance, dynamic geometry software (DGS) is nothing more than a drawing package. Yet a DGS is more than a simple program for graphics because the user can not only specify geometric relations between initial objects (such as points and lines) but can also grasp such objects and drag them. In a classroom research project (Jones 2000), the work of a class of 12-year-old pupils was analysed as they completed a module of work on the topic of the properties of quadrilaterals. The aim of the study was to document the meanings that pupils gained of deductive reasoning through experience with DGS software. It was anticipated that their meaning would likely be shaped, not only by the tasks they tackled and their interactions with their teacher and with other pupils, but also by features of the software. The evidence from the research study indicated that while using DGS does provide learners with a way of working with geometrical theorems, this is mediated by features of the software, especially in the vital early and intermediate stages of using the software.

This research project illustrates that even with carefully designed tasks, sensitive teacher input, and a classroom environment that encourages conjecturing and a focus on mathematical explanation, it can take quite some time for the benefits of using DGS to emerge. For example, learners take time to understand not only the uses that can be made of the facility to drag on-screen objects, but also what is entailed in constructing an onscreen figure in a way that fully utilises relevant geometrical theory. Not only that, but a particular issue is whether the opportunities offered with 
DGS to 'see' mathematical properties with such on-screen support might reduce or even replace any need for mathematical proof - or, on the contrary, whether new ways of promoting learners' understanding of the need for, and the roles of, proof might open up (Hoyles and Jones, 1998).

The theme of time also emerges when one considers what is involved in designing teaching and learning activities for geometry. Research on designing teaching scenarios based on various forms of geometry software, and of integrating them into the regular pattern of classroom teaching, shows that it can take quite a long time to reach the point where tasks genuinely take advantage of the computer environment (Brown et al, 2003; Christou et al 2006, 2007; Zachariades et al; 2007). Such research indicates that geometry tasks selected for use in the classroom should, as far as possible, be chosen to be useful, interesting and/or surprising to pupils. In addition, it can be helpful if classroom tasks expect pupils to explain, justify or reason, and be critical of their own and their peers' explanations. In particular, the generating of data or the use of measurements, while playing important parts in mathematics, and sometimes assisting with the building of conjectures, are probably best not an end point to pupils' mathematical activity. Indeed, where sensible and in order to build geometric reasoning and discourage over-reliance on empirical verification, classroom tasks might use contexts or approaches where measurements or other forms of data are not generated. In addition to taking time to reach the point where tasks genuinely take advantage of ICT, the issue of finding how to manage classroom time well during actual teaching is also something that research shows has to be worked on.

An especially interesting conundrum relates to using ICT for 3D geometry (Christou et al 2006; Jones, Mackrell \& Stevenson, 2009). It may seem, at first sight, rather odd to be working in 3D geometry on a flat 2D computer screen. Not only that, but the issue of representing 3D objects on a flat screen means that a number of design decisions, unique to 3D software, need to be made by software developers - one being the key decision of how the opening software screen both orients the user to 3D space, and provides a framework for the creation of 3D figures and structures. Inevitably, this has been tackled in different ways by different software developers, yet what learners make of such differences is currently underresearched. The issue that this pinpoints is that of just how 'direct' is what is often called 'direct interaction' when using ICT for geometry. As digital technologies develop, it is increasingly unclear whether learners do feel that they are interacting 'directly' with geometrical theory; what learners may experience is rapidly moving dynamic on-screen images that seem more like computer-generated trickery of the form found in contemporary movies. The question that remains open is how the learning of geometry can be facilitated through different digital technologies in a way which 
successfully builds upon the visual intuition that all of us require in order to understand our experience of physical and mathematical space.

The need to understand learners' use of interactive geometry software, and the need to be able to design suitable teaching and learning activities, points to the importance of research on forms of suitable teacher professional development. In a project involving experienced teachers collaborating in developing ways of providing professional development and support for other teachers (Jones, Lavicza, Hohenwarter, Lu, Dawes, Parish \& Borcherds, 2009), a particularly promising approach to stimulating professional conversations about teaching approaches was the framework illustrated in Figure 5.2.

In the teacher-demonstration approach, the teacher engages students in discussing an on-screen geometric construction by, perhaps, asking questions about the objects on the screen in order to get the learners to explain what they might expect would happen if some parts of the configuration were moved or changed. In the project, this approach was found to allow teachers with little experience of using technology in the classroom to experiment with the technology with relatively small risk. In addition, this kind of use requires less change in the classroom setting and needs fewer resources than either organising classes into a computer room or using a class set of laptops in the regular classroom.

The second approach (in Figure 2) entails teachers providing previously created interactive files for their learners. With such teacher-created files, students can experiment with dynamic objects. This provides clear boundaries for learners and time is not spent setting up the tasks; rather, learners can spend time exploring the mathematics that is central to each task. No doubt there is quite some teacher control over the material, but the approach can bring in opportunities for creative thinking and problem solving by learners. The third approach (in Figure 2) involves learners creating their own files, perhaps for other learners to tackle. This approach

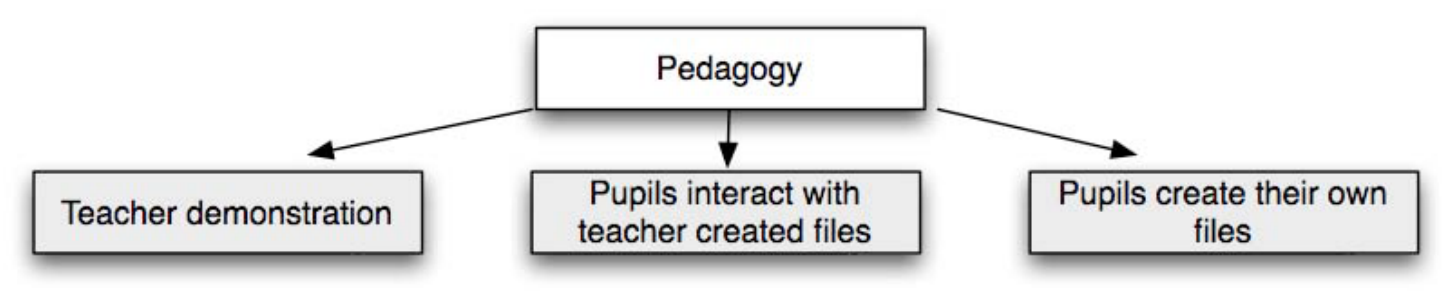

FIGURE 5.2: framework of teaching approaches with geometry software 
provides some learner ownership of the work and engages a different sense of problem solving (and problem posing) by creating that ownership. There is also the development of independence - in learning how to use the software, and with additional scope for student creativity and discovery. In the research project, this framework of teaching approaches provided both a way of structuring discussion during teacher CPD sessions, and a prompt for further discussion and further work - supported online through the provision of a wiki via which participants collaborated. All this points to ways in which teaching approaches developed by teachers can be used to stimulate further professional development through creating a network of teachers who are looking to enhance their use of ICT in the teaching and learning of geometry.

Given these findings from research, it is instructive to note that the first issue of BJET (in 1970) included a review of Oettinger's (1969) book on the 'mythology of educational innovation'. In this book, Oettinger concluded that, at the time, "education technology has not reformed - much less revolutionized - education" (ibid, p215). This prompted the BJET reviewer to observe that the major contribution of the book was that of "alerting educators... to unrealistic technological expectations and heading off widespread disenchantment which might hinder the progress of educational technology” (Saettler, 1970; p 79).

\section{Conclusion}

The main message of this chapter is that the undoubted, and so far unparalleled, affordances of ICT, must be measured against the complexity of classroom learning, the demanding role for the teacher, and the need for well-tuned relevant professional development opportunities. While access to computing power may shortly no longer be a source of an unbridgeable 'digital divide', differential access to networks of people that provide support for, and nurturing of, educational innovation via ICT may be an emerging new form of 'digital divide'.

As Oettinger (1969) warned some forty years ago, it can be that expectations of technology appear unrealistic. Even with a classroom with suitable (and reliable) equipment, and with supportive institutional and national policies, such things may not be enough to counter Ofsted's claim that school teaching of mathematics in England makes a "relatively limited contribution to developing pupils' ICT skills" and that "despite technological advances, the potential of ICT to enhance the learning of mathematics is too rarely realised" (Ofsted, 2008, p27). 
In developmental psychology, the notion of canalization has been widely invoked, mostly in a nurture/nature argument (see, for example, Gottlieb, 1991), as a way of capturing the idea that there is a 'normal' pathway of development and that this can withstand "great assaults or perturbations and still return to (or remain on) its usual developmental pathway" (op cit, p4). This idea of canalization might have the potential to illuminate, at least to some extent, the issue at the heart of this chapter - that of why, despite the widely-acknowledged potential of ICT, its integration into mathematics teaching and learning has proceeded much more slowly than some have predicted. It could be that the 'normal' pathway of educational change over time is one that innovative technology (be it the $16 \mathrm{~mm}$ film projectors of the late 1960s, or the hand-held multi-media smart phones of today) on its own may not perturb enough to cause a major change. Perhaps when more is known about learners' use of interactive software, the design of appropriate teaching and learning activities, and the nature of suitable teacher professional learning and development - and this is matched by supportive institutional and national policies - then the potential of ICT to enliven mathematics teaching and learning may be more likely to reach a 'tipping point' and move the pathway of education to a radically new route.

\section{References}

Brown, M., Jones, K. \& Taylor, R. (2003), Developing Geometrical Reasoning in the Secondary School: outcomes of trialling teaching activities in classrooms, a report to the QCA. London: QCA.

Christou, C., Jones, K., Mousoulides, N., \& Pittalis, M. (2006). Developing the 3DMath dynamic geometry software: theoretical perspectives on design, International Journal of Technology in Mathematics Education, 13(4), 168174.

Christou, C., Sendova, E., Matos, J-F., Jones, K., Zachariades, T., PittaPantazi, D., Mousoulides, N., Pittalis, M., Boytchev, P., Mesquita, M., Chehlarova, T. \& Lozanov, C. (2007), Stereometry Activities with DALEST. Nicosia, Cyprus: University of Cyprus.

Gottlieb, G. (1991), Experiential canalization of behavioral development: theory. Developmental Psychology, 27, 4 - 13.

Hoyles, C. \& Jones, K. (1998), Proof in dynamic geometry contexts. In: C. Mammana and V. Villani (Eds), Perspectives on the Teaching of Geometry for the 21st Century (ICMI Study 8). Dordrecht: Kluwer. pp121-128.

Jones, K. (2000), Providing a foundation for deductive reasoning: students' interpretation when using dynamic geometry software and their evolving mathematical explanations. Educational Studies in Mathematics, 44(1-3), 55-85. 
Jones, K. (2002a), Issues in the teaching and learning of geometry. In: Linda Haggarty (Ed), Aspects of Teaching Secondary Mathematics. London: Routledge. pp 121-139.

Jones, K. (2002b), Research on the use of dynamic geometry software, MicroMath, 18(3), 18-20.

Jones, K., Lavicza, Z., Hohenwarter, M., Lu, A., Dawes, M., Parish, A. \& Borcherds, M. (2009), Establishing a professional development network to support teachers using dynamic mathematics software GeoGebra, Proceedings of the British Society for Research into Learning Mathematics, 29(1), 97-102.

Jones, K., Mackrell, K. \& Stevenson, I. (2009), Designing digital technologies and learning activities for different geometries. In Celia Hoyles and Jean-Baptiste (eds), Mathematics Education and Technology: Rethinking the Terrain (ICMI Study 17). New York: Springer. Chapter 4, pp47-60.

Ofsted (2008), Mathematics: understanding the score. London: HMSO.

Oettinger, A. G. (1969), Run, Computer, Run: the mythology of educational innovation. Cambridge, MA: Harvard University Press.

Saettler, P. (1970), An essay of mythology, British Journal of Educational Technology, 1(1), 74-79.

Zachariades, T., Jones, K., Giannakoulias, E., Biza, I., Diacoumopoulos, D., \& Souyoul, A. (2007), Teaching Calculus using Dynamic Geometric Tools. Athens, Greece: University of Athens. 